\title{
MEMÓRIA, HISTÓRIA E EDUCAÇÃO ${ }^{1}$
}

Sérgio Eduardo M. Castanho
FE - UNICAMP

RESUMO

Nos dias atuais a memória veio para o primeiro plano das questões acadêmicas, de certa maneira deslocando discretamente a história. Considero a memória o principal nutriente da história. Mas não se identifica com ela. A memória é bem mais confiável e objetiva do que se poderia supor. E a história, tendo progredido teórica e metodologicamente, apresenta-se hoje como uma ciência da qual é justo esperar resultados bem mais significativos para o indivíduo e a sociedade do que o historicismo relativista faria crer. Nem sempre a sociedade se lembra; muitas vezes, a sociedade, e em especial a sua camada dominante, esquece-se. A memória lembra e a história recompõe o movimento da sociedade humana no tempo. A história cultural é legítima, não porque toda história seja cultural, mas porque é possível uma história do âmbito cultural com relativa autonomia. A história cultural tem seu âmbito próprio, sem deixar de ser história. E a história da educação acaba também por se constituir como campo autônomo, dotado de objeto próprio, ainda que tangenciando outras disciplinas históricas ou com elas caminhando junto. Por fim, nunca é demais reiterar que a história deve ser vista de um ponto de vista globalizante e unitário. E a história da educação, especialidade disciplinar recente, ganha legitimidade justamente na medida em que se articula com a totalidade histórica. Com essa condição, ela pode estudar objetos mínimos como certas instituições escolares individuais, mas com subordinação ao processo geral da institucionalização escolar, dentro do processo histórico da escolarização da educação, que por sua vez se situa no processo mais amplo da produção manufatureira, que por seu turno é um episódio da cooperação produtiva, que constitui uma realização histórica do processo de produção material da existência, que é, ao fim e ao cabo, a determinação básica de toda a história.

Palavras-chave: História da Educação; História Cultural; memória

\section{MEMORY, HISTORY AND EDUCATION}

\section{ABSTRACT}

Nowadays the memory came to the foreground of the academic issues, somehow quietly shifting the story. It is possible to consider the memory the main nutrient of history. But it doesn't identify with the second. Memory is much more reliable and objective than one might assume. And the story, having progressed theoretically and methodologically, presents itself today as a science of which is fair to expect good results more meaningful for the individual and society than the relativist Historicism would believe. Society doesn't always remember; often, society, and in particular its dominant layer, forget. Memory remembers and History reassembles the movement of human society at the time. The cultural history is legitimate, not because the whole story is cultural, but because it is possible a cultural history with relative autonomy. The cultural history has its own scope, but is always history. And the history of education has just also been constituted as a field with own object, although other historical disciplines surfacing or walking together. Finally, it never hurts to reiterate that history should be viewed from a global and unitary viewpoint. And the history of education, a new specialty discipline, won legitimacy precisely to the extent that articulates with the entirety of history. With this condition, it can study small objects like certain individual educational institutions, but subject to the 
overall process of institutionalization, within the historical process of schooling of education, which in turn lies in the wider process of manufacturing production, which in turn is an episode of the productive cooperation, which constitutes a historic achievement in the production process of material existence that is, after all, the determination of the whole story.

Keywords: History of Education; Cultural History; memory

Nos dias atuais a memória veio para o primeiro plano das questões acadêmicas, de certa maneira deslocando discretamente a história. Por quê? Trabalho com a hipótese de que isso se deva ao movimento geral nas oficinas das ciências humanas para tirar peso científico às humanidades. A explicação, no seio das humanidades, cedeu lugar à impressão, a narração sistemática dos feitos humanos perdeu passo para o discurso pitoresco, a memória subiu ao pódio deslocando a história. Os centros de memória multiplicaram-se no mesmo passo em que os institutos históricos se apequenaram. Nem sempre isso foi tão explícito. Muitas vezes a denominação histórica permaneceu mas destituída de conteúdo explicativo, preferindo-se a narração fatual dos acontecimentos passados à recomposição do movimento real das sociedades humanas, com a perda de seu componente interpretativo, que por sua vez é o primeiro requisito para a intervenção crítica no rumo dessas sociedades. O fim da história, proclamado por Fukuyama, é o reino da memória, da lembrança plácida do passado, num exercício de enaltecimento oco deste, com seus vultos heróicos, suas datas inesquecíveis e também suas datas obliteráveis porque discutíveis e questionadoras.

Mas se estou discorrendo assim calmamente sobre memória e história, dou de barato que os respectivos conceitos estejam decididos e nada há que dizer a seu respeito. Pelo contrário. A discussão está aberta. É preciso remexer nas concepções de história e memória. É necessário ter uma teoria da história e uma teoria da memória para ver que ambas, longe de se excluírem, se complementam. Mais ainda: isso tudo é preciso para que a intervenção na sociedade, tão necessária em tempos de carências tão fundas, seja possível a partir de bases sólidas, que somente o conhecimento científico pode fornecer. E, em falando em intervenção social, vem à baila o terceiro elo de nosso título, a educação. Vamos então começar do princípio, revisitando os conceitos de memória, história e educação, para então estabelecer entre eles os necessários nexos.

Sem memória não há história. Desde Tucídides a história narra o de que a memória se lembra. A diferença é que hoje não há a necessidade do testemunho presencial do narrador, substituído pelas fontes, tanto duras, documentais, probantes, quanto indiciárias, mais leves.

Considero a memória o principal nutriente da história. Mas não se identifica com ela, assim como a semente não é o passarinho que não obstante nutre. A memória é algo de mais substantivo, tanto do ponto de vista do objeto quanto do sujeito. Objetivamente, a memória é aquilo que se lembra, acontecimentos, fatos, sentimentos, sensações e significados, tudo aquilo que passou pelo campo de percepção do indivíduo e pelas antenas da sociedade, sendo retido por um e por outra e devolvido diante de qualquer necessidade. Subjetivamente, a memória é o ato de lembrar, individual ou coletivamente, compreendendo, na sua complexidade, tanto o momento de fixação quanto o de devolução. 
Já a história é mais adjetiva, comportando, de uma parte, os fatos acontecidos e os processos desenvolvidos, no sentido de res gestae, e, de outra parte, o conhecimento organizado e sistemático desses fatos e processos, no sentido de historia rerum gestarum. Explico por que considero esse material e esse conhecimento como mais adjetivos. É que eles implicam uma seleção, uma atribuição de qualidade, o que é próprio do adjetivo. A seleção começa pelos fatos que a sociedade considera "dignos de memória" e se completa pela nova seleção e pela organização que lhe faz o historiador. De tudo isso, provisoriamente, gostaria de insistir na distinção entre memória e história, não obstante a profunda imbricação, eu diria a indissociabilidade que os dois termos possuem, notadamente quando observados do ponto de vista mais organizativo, que é o da história.

A memória, desenvolvida durante a já longa história da sociedade humana, mediante $\mathrm{o}$ aperfeiçoamento dos processos e procedimentos mnemônicos e mnemotécnicos, é bem mais confiável e objetiva do que se poderia supor. E a história, tendo progredido teórica e metodologicamente, apresenta-se hoje como uma ciência da qual é justo esperar resultados bem mais significativos para o indivíduo e a sociedade do que o historicismo relativista faria crer. Isto não significa que não haja os lapsos da memória - individual ou coletiva - nem que a memória deixe de se ajustar aos contingenciamentos da existência individual e grupal, que levam às amnésias parciais ou totais, onde mecanismos como os do poder não são nem um pouco negligenciáveis.

O mesmo se pode dizer da história. Os fatos históricos não se constituem como "fatos" da maneira cândida como o positivismo quer inculcar. Com efeito, o fato histórico, na visão positivista, se encaixa numa sequência evolucionária rígida, marcada pela tangibilidade (o fato é coisa, pode ser tocado) e pela explicação cronológica sucessiva (os fatos anteriores explicam os posteriores pela pura e simples antecedência). Não penso assim. Ao revés, os fatos se tornam "fatos históricos", referendados pela memória cultural, na medida em que são conformados pela construção conflitiva da existência social, essa arena onde se digladiam interesses opostos gerados na contínua luta pela vida, a struggle for life da consagrada expressão darwiniana ou a irremediável dialética da produção da vida social em linguagem mais cara à tradição marxista. Isto da parte dos fatos. Quanto ao seu conhecimento e organização num corpus explicativo, ou, caso se preferir, num discurso científico, este pode perfeitamente pretender à objetividade, sem embargo de sua não neutralidade, isto é, de seu aprisionamento aos interesses de classe, como mostrou Gramsci na sua Concepção dialética da história (1984). De certa maneira, mesmo Weber também apontou essa não neutralidade, ao condicionar o conhecimento histórico às malhas do poder, com a diferença de que Weber, por esse motivo, acabou engrossando as fileiras do historicismo da escola de Dilthey. Já para Gramsci, permanece aberta a possibilidade de estatuto científico à história, que só não pode reclamar-se de neutralidade. É importante lembrar que Gramsci, por exemplo, também não aproximava todo discurso ideológico da "falsa consciência", reservando esta ao discurso de dominação, ainda mesmo quando este pudesse conter aspectos ou fragmentos de verdade histórica.

Podemos entrever dois tipos de memória, a individual e a cultural, esta última também dita coletiva ou compartida. No seu clássico ensaio sobre a matéria, Le Goff, colocando a memória na linha do tempo (num "estudo histórico da memória histórica"), considerou dela cinco modalidades, que correspondem "às fases de transição da oralidade à escrita" (LE GOFF, 1996, p. 426-427). O estudo é apaixonante e a ele remeto os interessados, que aí encontrarão elementos para uma teoria histórica da memória de primeiro quilate, desde que temperada cum mica salis, o sal suficiente para dar movimento histórico ao que poderia ser uma simples sucessão. Entretanto, o apelo com que o autor 
encerra o capítulo é digno de transcrição: "A memória, onde cresce a história, que por sua vez a alimenta, procura salvar o passado para servir o presente e o futuro. Devemos trabalhar de forma a que a memória coletiva sirva para a libertação e não para a servidão dos homens." (LE GOFF, op. cit., p. 477).

Qual o papel da memória individual? A bem dizer, ela diz respeito à recordação de fatos, ditos, feitos, percursos e até mesmo de situações mais complexas envolvendo cheiros, como em Proust, sentimentos vividos, emoções, habilidades, artes do fazer, como dizia Certeau, em suma, tudo aquilo que, vindo do passado, se incorpora ao patrimônio profundo do indivíduo e que, em certo momento, é trazido à tona para se fazer intervenção no mundo presente.

Essa memória individual é o fundamento da noção de "eu", daquilo a que chamamos a identidade pessoal. Isso não significa que ela seja despojada de aspectos da memória social do grupo ou classe social de que o indivíduo é originário. Pelo contrário! No indivíduo subsistem os fundamentos de sua identidade pessoal, calcados na memória individual, juntamente com os traços da cultura em que ele foi formado, em que continua sendo formado. Vistas as coisas adequadamente, não há um limite para a formação, razão por que os educadores contemporâneos batem na tecla da formação continuada. Segundo Viñao Frago, a memória individual "responde à pergunta: de onde venho?, prepara a resposta à: onde estou?, e antecipa o: aonde vou?" (VIÑAO FRAGO, 1996, p. 34).

Quanto à memória cultural, coletiva ou compartida, diz respeito à sociedade onde se inserem os indivíduos, numa gradação que admite diferentes patamares de socialização. Tal como a individual, mas de maneira ainda mais intensa, ela necessita de suportes empíricos (orais, textuais, imagéticos), de lugares, ditos "lugares da memória" (como os monumentos, os museus, as bibliotecas, os arquivos), e de práticas sociais (como as comemorações, o calendário, festividades leigas e religiosas, etc.).

Essa socialização da memória, ou, correspondentemente, essa memorização do social, apresenta uma armadilha lógica, quer dizer, a correspondência não é biunívoca, mas equívoca. De fato, nem sempre a sociedade se lembra; muitas vezes, a sociedade, e em especial a sua camada dominante, esquece-se. Via de regra, a voz do passado é a voz dos vitoriosos, apagando-se os vestígios dos vencidos. Isso porque a lógica dominante é a lógica dos dominantes.

A memória coletiva se expressa no âmbito de instituições, tanto da sociedade política quanto da sociedade civil, como igrejas, escolas, sociedades históricas e assim por diante. As estatais são a voz do poder. Nas instituições da sociedade civil misturam-se as vozes dos dominantes e dos dominados, de tal sorte que se podem encontrar memórias de lutas operárias nos sindicatos e hoje até mesmo em universidades. Viñao Frago acrescenta:

A memória coletiva como instrumento de poder foi o que tornou possível o arquivo, a biblioteca e o museu, todos eles lugares de conservação, recuperação e esquecimento, por antonomásia, da mesma. Sua transmissão e ensino, a transmissão do saber coletivo, se confiou em parte, cada vez mais, também de um modo específico, à escola e ao mundo acadêmico. Houve e há outros lugares de produção da memória coletiva. Por exemplo: o religioso, o familiar, o associativo e o laboral. Mas o arquivo e a biblioteca, juntamente com o museu, a escola e a erudição, são, diferentemente dos anteriores, instituições especificamente criadas e configuradas para conservar, recriar e transmitir tanto a 
memória e o saber reunidos quanto os silêncios e esquecimentos acumulados (VIÑAO FRAGO, op. cit., p. 35).

A memória coletiva está para a sociedade, em termos identitários, como a memória individual está para cada pessoa. Aquilo que se chama a identidade nacional - ou, de um modo genérico, a identidade social - assenta na memória de um passado comum, ou pelo menos tido como comum. Por certo, o que fica como sendo comum, localizável ou não - e neste último caso temos o mito fundador, a que alude Marilena Chauí (2000, p. 9), que prende com as origens do grupo, lançadas nas brumas de um passado obscuro, - é algo como um sinal que orienta e conduz para o futuro.

A reconstrução histórica para fins de consolidação da identidade grupal é o que se faz nas comemorações, tanto laicas, como a festa do dia da Independência, quanto religiosas, como a data consagrada à padroeira do Brasil. Ao transformá-las em feriados e instituir práticas comemorativas, o Estado erige-as em manifestações de poder, e especificamente do poder de representar o ente coletivo pela assunção, evocação e exaltação de seu passado. Tais manifestações vão desde as mais diretas, como as paradas militares, até às mais sutis, de natureza cultural. O discurso histórico, a cargo de "historiadores oficiais" ou mesmo seus sucedâneos entre as autoridades, desempenha um papel muito importante na definição, caracterização e significação dessa memória social.

Não se esqueça, porém, que a comemoração, por ser promovida por aqueles a quem ela aproveita, suscita a contracomemoração, que ressignifica o mesmo material de memória social da comemoração, e também o esquecimento, que é a postura ativa de amnésia, por parte do grupo ou dos grupos da sociedade civil que rejeitam o sentido que o establishment comemorante empresta à memória social. Em outras palavras, a luta de classes permanece no mundo cultural.

Pois bem: a memória lembra e a história recompõe o movimento da sociedade humana no tempo. Pode-se então fazer a pergunta: é possível pensar o futuro?

Comecemos por dizer, com Hobsbawm, que o passado, o presente e o futuro constituem um continuum. Como diz com sua proverbial facilidade o historiador inglês, o que acabo de falar pertence ao passado e o que estou prestes a dizer pertence ao futuro, sendo o presente um ponto qualquer de intersecção caracterizado pela fugacidade. A humanidade, seja pelos indivíduos, seja pelas sociedades, está sempre referindo-se ao passado, ao mesmo tempo em que projeta suas ações para o futuro. Hobsbawm:

E mais, a maior parte da ação humana consciente, baseada em aprendizado, memória e experiência, constitui um vasto mecanismo para comparar constantemente passado, presente e futuro (HOBSBAWM, 1998, p. 50).

Eu diria que, partindo de um historiador marxista, preocupado com os movimentos de idas e vindas entre as singularidades, as particularidades e as totalidades, Hobsbawm certamente reserva a previsibilidade para aquilo que a tradição marxista designa como "leis tendenciais" da história, respeitantes às grandes estruturas da sociedade. Quais as seções do futuro vedadas aos oráculos togados das academias? Aquelas que respeitam às singularidades e particularidades. Em termos menos genéricos, seriam os fatos e feitos dos indivíduos, os fatos e feitos dos grupos sociais, inclusive os das classes sociais, que se fazem e desfazem no decurso da história. O que seria mais estável e portanto mais 
previsível? O conflito, como acentua Thompson na obra As peculiaridades dos ingleses $e$ outros artigos (2001).

Mais cômodo seria, como admite o próprio Hobsbawm, dizer que o ofício do historiador confina-o ao território do passado. Mas não é possível afirmar isso e continuar, por outro lado, a insistir nas vantagens que o conhecimento histórico traz para a vida humana.

De acordo com as famosas "leis tendenciais" entrevistas por Marx na sua análise do capitalismo, é possível afirmar que a globalização é um processo ínsito ao modo de produção capitalista e que ela continuará se expandindo enquanto esse modo de produção persistir como dominante. A globalização esteve presente no nascimento do capitalismo, no fim do século XV, início do século XVI, no sentido de uma expansão do mercado em âmbito mundial, como o notou com riqueza de detalhes um historiador não marxista, Fernand Braudel, na sua obra em três volumes Civilização material, economia $e$ capitalismo: séculos XV-XVIII (BRAUDEL, 1995). Essa mesma globalização, em diferentes formas, subsistiu nos cinco séculos seguintes, em "marés" sucessivas (CASTANHO, 2001), subsiste hoje e nada indica que deixará de existir enquanto perdure o modo de produção de que ela constitui um dos pilares, juntamente com a acumulação ampliada do capital e a exploração da mais-valia do trabalho. É evidente, por outro lado, que todo processo de expansão encontra resistências. Dessa forma, é provável que a globalização contemporânea, ao friccionar com interesses localizados, provoque conflitos, talvez guerras. Onde? Quando? Aqui nossa cautela redobra. Poderemos localizar pontos "quentes" do planeta onde a probabilidade da eclosão de conflito armado seja maior. Mas não podemos afirmar o onde e o quando sob pena de quebrarmos o compromisso com uma visão histórica de totalidade, não de parcialidade.

Vou citar uma vez mais Hobsbawm, que, à semelhança do sábio chinês, reduz o alcance de seu saber até ao máximo, ao mesmo tempo em que, por entre as dobras da modéstia, deixa entrever a grandiosidade de seu pensar: "A história só fornece orientação, e todo aquele que encarar o futuro sem ela não só é cego mas perigoso, principalmente na era da alta tecnologia." (HOBSBAWM, 1998, p. 64).

Em uma síntese difícil mas necessária podemos dizer que:

a) A memória, especialmente a individual, não é a solução para todos os problemas historiográficos, como pretende uma certa visão fragmentária da história, muito ao gosto pós-moderno. De qualquer forma, a memória é nutriente da história e merece a importância que se lhe dá na teoria da história contemporânea.

b) O tempo presente é objeto da história e até se constitui no principal fornecedor de categorias para análise da história passada, conforme a magistral lição de Marx. Isto não leva ao presentismo, com justeza criticado por Schaff. Mas leva ao intervencionismo, reclamado por Josep Fontana, que é a tendência, aberta pelo estudo da história, à atuação social consciente no sentido de humanizar o mundo presente.

c) O futuro não pode ser conhecido na sua inteireza, mas é possível conhecer as tendências do seu desenho com vistas a uma inserção consciente de ação social.

Para entrar na questão das relações entre a história e a educação, é preciso fazer uma passagem pela história cultural, procurando, antes de tudo, evitar os malentendidos que a simples enunciação dessa disciplina costuma aflorar.

No sentido de ultrapassar esses desvios, quero desde já adiantar que, quando me refiro à história cultural, não estou me postando entre os cultores da chamada "nova história cultural" nem mesmo entre os que têm da história em geral uma visão culturalista. Refiro-me à história cultural como um segmento da ciência una e única da história, praticamente como "história da cultura" ou, ainda mais precisamente, como história que 
leva em conta, como Marx apontou nos Grundrisse (1985, 1986a, 1986b), a importância da dimensão cultural da existência social humana. Mais à frente tratarei das relações entre a história cultural e a educação, momento em que também procurarei apontar as interseções, os entrecruzamentos e as possibilidades de cooperação entre a história cultural e a história da educação.

É preciso esclarecer que aceito a história cultural como legítima, não porque toda história seja cultural, como pretendem os que a tomam num sentido substantivo, como sinônimo de "a" história, mas sim num sentido adjetivo, que admite a possibilidade de uma história do âmbito cultural com relativa autonomia. Que fique bem claro: relativa autonomia. Emprestar-lhe absoluta autonomia seria desvinculá-la das determinações materiais que lhe conferem realidade. Mas, por outro lado, evito também trazê-la o tempo todo a reboque de raízes econômicas, numa redução da determinação material à determinação econômica (economicismo) que não estava nem no pensamento dos iniciadores do marxismo nem no de seus mais lúcidos continuadores. Posiciono-me, portanto, numa vertente da história cultural a que denomino contextualista. Vejo no seu objeto, a cultura, indisfarçável materialidade, de tal forma que me identifico com o materialismo cultural de Raymond Williams.

Isso posto, passo a examinar as relações possíveis entre a história, a história cultural e a educação, o que inclui, é óbvio, a história da educação.

No passado, muitas classificações compreenderam a educação dentro do campo da história cultural. É que a história da educação, ainda que praticada desde o século XIX (como "história da pedagogia" ou do pensamento educacional), demorou a se firmar como disciplina relativamente autônoma.

Observando com atenção o esquema geral da obra de 1943 de Fernando de Azevedo, A cultura brasileira (1963), poderemos observar a subordinação da espécie educação ao gênero cultura. De fato, a cultura, nos seus fatores determinantes, ocupa a primeira parte do livro; nas suas manifestações individuais e institucionais, a segunda parte; e apenas entra, como educação, no sentido de "transmissão da cultura", na terceira parte.

A visão de cultura de Fernando de Azevedo era elitista, correspondendo a um estágio "superior" de desenvolvimento humano. A tal visão elitista, evolutiva, estratigráfica, contrapõe-se a da antropologia cultural contemporânea, que vê a cultura como uma "teia de significados". Tal é a visão de Clifford Geertz (1978), que, depois de assim a definir (p. 15), acrescenta:

Como sistemas entrelaçados de símbolos interpenetráveis (o que eu chamaria símbolos, ignorando as utilizações provinciais), a cultura não é um poder, algo a que podem ser atribuídos casualmente os acontecimentos sociais, os comportamentos, as instituições ou os processos; ela é um contexto, algo dentro do qual eles podem ser descritos de forma inteligível - isto é, descritos com densidade (GEERTZ, 1978, p. 24).

Como teia, a cultura é o referencial obrigatório para a inteligibilidade do social. Mas ela não é causa dos acontecimentos sociais, como gostaria de ser vista pelo culturalismo. As causas têm que ser encontradas em outro lugar, na produção material da existência. Mas uma ciência social interessada na interpretação dos fenômenos sociais 
(acontecimentos, comportamentos, instituições e processos) não pode deixar de considerar esse mundo simbólico. A história aí tem muito o que fazer. Como diz um historiador:

da cultura do próprio tempo e da própria classe não se sai a não ser para entrar no delírio e na ausência de comunicação. Assim como a língua, a cultura oferece ao indivíduo um horizonte de possibilidades latentes uma jaula flexível e invisível dentro da qual se exercita a liberdade condicionada de cada um (GINZBURG, 1987, p. 27).

É possível, inclusive para tentar dirimir o falso conflito cultura versus ideologia, pensar na função que Gramsci assinalava à ideologia como "cimento" do bloco histórico, isto é, uma amarração que vincula, numa soldadura unificante, diversos elementos, na verdade manifestações dessa cola universalizante. Na visão gramsciana, a unidade do bloco histórico, ou seja, a unidade dialética (cortada por tensões) entre a estrutura social e a superestrutura, é garantida pela ideologia. É pela ideologia que as pessoas tomam consciência de sua posição na sociedade. O estudo da formação ideológica e dos grupos sociais especializados em operar no nível superestrutural (os intelectuais) é uma das partes mais instigantes da obra do pensador italiano (GRAMSCI, 1982). Mas é importante destacar que Gramsci, mesmo utilizando-se de um conceito ampliado de ideologia, não descartava o de cultura. É possível dizer, nas pegadas do pensador italiano, que a ideologia é a própria cultura enquanto se torna o discurso do interesse de determinado grupo social.

Voltando à visão de cultura como teia, é necessário acrescentar que, numa tal concepção de cultura, existe um forte trânsito bidirecional, da teia para as partes, destas para a teia. Do ponto de vista do observador, é difícil dizer se a percepção é inicialmente das partes e depois do todo ou vice-versa. É que, em se tratando de um processo, há os "momentos" da totalidade e das partes, nenhum podendo existir sem o outro. A dialética, que assume o processo como totalidade, é a saída para o impasse.

Então a história cultural, abrangendo a totalidade do processo, seria a história, pura e simplesmente? Não penso assim. A história, como todos os modos de conhecimento do real, especializou-se com o passar dos tempos. Não posso dizer que o objeto da história econômica e o da história cultural sejam o mesmo. A formação das disciplinas científicas é um campo que compete ao historiador estudar (ver, por exemplo, Chervel, 1990) e, nesse estudo, não há por que não incluir a formação das especializações historiográficas. No entanto, se Marx considerava o conhecimento da sociedade uma "ciência unitária", nem por isso deixou de atentar para suas diversidades provinciais. Diz Viñao Frago, parafraseando Richard Schoenwald, "que a história social é sempre história cultural, a história cultural, sempre história social, e que ambas finalmente são somente história" (VIÑAO FRAGO, 1995, p. 65). Essa história una reparte-se num grande número de disciplinas históricas, que são como que "etiquetas" que a academia lhe prega, na tarefa cartesiana de dividir o real em fragmentos para mais comodamente poder estudá-lo - ou, se quisermos, para acomodar uma crescente população acadêmica na divisão do poder institucional. Temos, assim, uma especialização epistemológica correndo paralelamente a uma especialização política.

Assim, a história cultural tem seu âmbito próprio, sem deixar de ser história. E a história da educação, depois de um longo itinerário, acaba também por se constituir como campo autônomo, dotado de objeto próprio, ainda que tangenciando outras disciplinas históricas ou com elas caminhando junto. Considerando, com Lucien Goldmann, que a 
história se ocupa com "as transformações da sociedade humana" (1967, p. 23) e, com Vigotski, que "estudar alguma coisa do ponto-de-vista histórico significa estudá-la em seu processo de mudança; esta é a exigência básica do método dialético." (apud Viñao Frago, op. cit., p. 76), pensamos que a história da educação ocupa-se com o fenômeno educativo na medida em que se transforma. Basicamente, o campo do fenômeno educativo, na sociedade moderna (pós-medieval), abarca as práticas predominantemente escolares (embora também se vislumbrem as extra-escolares) da educação, suas representações (o pensamento educacional, as propostas educacionais) e a regulamentação dessa atividade (legislação educacional, políticas educacionais), nas suas transformações no espaço e no tempo.

A força teórica e metodológica do materialismo histórico, isto é, sua validade como instrumento de acesso e de explicação do fenômeno educativo em mudança, depende em grande medida da sua capacidade de adaptação aos novos objetos, aos novos problemas e até mesmo aos procedimentos (não métodos) que chegam junto com as novas temáticas. Já vimos como o marxismo de um Thompson, por exemplo, ao se defrontar com uma nova questão para a qual os velhos instrumentos não davam conta, acabou por se rever, por se reformular, encontrando novos caminhos. O mesmo seguramente deverá ocorrer na área da história da educação, se o enfoque quiser dar conta de outras questões além das extremamente válidas e importantes do pensamento pedagógico e da política educacional.

Por fim, nunca é demais reiterar que considero a história do ponto de vista globalizante e unitário do qual ela foi mirada por Marx e Engels. Nesse sentido, sendo histórico todo conhecimento, a história aparece como "ciência diretora" de todo conhecimento.

Não quero com isso dizer que a história, como conhecimento específico do movimento de mudança das sociedades humanas, não possua seus protocolos, seu modo específico de tratar das questões que lhe são submetidas. E também não se segue que a história, nesse sentido, deixe de ter suas categorias estruturantes. Os protocolos e as categorias básicas da história são firmemente determinados sem que se perca a sua característica de direção geral de todo o conhecimento. A história tem uma determinação geral inocultável, que é a da produção material da existência humana.

Não obstante o caráter totalizante e unitário que possui, a história oferece-se, na lida acadêmica, em múltiplas especializações. Estas não quebram a totalidade e a unidade da história. São simples tratamentos específicos de dimensões diversas da realidade social. Dessa maneira, são legítimas formas historiográficas as que tratam da questão populacional (história demográfica), da questão do poder (história política), da questão da produção, circulação e consumo de bens e serviços (história econômica), da questão simbólica (história cultural), da questão da formação humana (história da educação) e assim por diante. Essa legitimidade, entretanto, depende da contínua articulação entre o domínio específico tratado e a totalidade histórica.

A história cultural é uma disciplina científica viável, com objeto próprio específico, sem qualquer pretensão a abarcar a totalidade do conhecimento histórico, mas dependente desta para a determinação da sua problemática especial localizada no âmbito simbólico.

Igualmente, a história da educação, especialidade disciplinar mais recente, ganha legitimidade justamente na medida em que se articula com a totalidade histórica. Com essa condição, ela pode estudar objetos mínimos como certas instituições escolares individuais, 
mas com subordinação ao processo geral da institucionalização escolar, dentro do processo histórico da escolarização da educação, que por sua vez se situa no processo mais amplo da produção manufatureira, que por seu turno é um episódio da cooperação produtiva, que constitui uma realização histórica do processo de produção material da existência, que é, ao fim e ao cabo, a determinação básica de toda a história.

\section{Referências}

AZEVEDO, Fernando de. A cultura brasileira. 4. ed. rev. amp. Brasília: Ed. UnB, 1963.

BRAUDEL, Fernand. Civilização material, economia e capitalismo: séculos XV-XVIII. Trad. Telma Costa. São Paulo, Martins Fontes, 1995. 3 v.

CASTANHO, Sérgio. Globalização, redefinição do estado nacional e seus impactos. In: LOMBARDI, José Claudinei (org.). Globalização, pós-modernidade e educação: história, filosofia e temas transversais. Campinas, SP: Autores Associados: HISTEDBR: Caçador, SC: UnC, 2001.

CHAUÍ, Marilena. Brasil: mito fundador e sociedade autoritária. São Paulo: Fundação Perseu Abramo, 2000.

CHERVEL, André. História das disciplinas escolares: reflexões sobre um campo de pesquisa, Teoria \& Educação, Porto Alegre, n. 2, p. 177-229, 1990.

GEERTZ, Clifford. A interpretação das culturas. Rio de Janeiro: Zahar, 1978.

GINZBURG, Carlo. O queijo e os vermes: o cotidiano e as idéias de um moleiro perseguido pela Inquisição. São Paulo: Companhia das Letras, 1987.

GOLDMANN, Lucien. Ciências humanas e filosofia. Trad. Lupe Contrim Garaude e J. Arthur Giannotti. São Paulo: Difusão Européia do Livro, 1967.

GRAMSCI, Antonio. Concepção dialética da história. 5. ed. Trad. Carlos Nelson Coutinho. Rio de Janeiro: Civilização Brasileira, 1984.

GRAMSCI, Antonio. Os intelectuais e a organização da cultura. 4. ed. Rio de Janeiro: Civilização Brasileira, 1982.

HOBSBAWM, Eric J. Sobre história. Trad. Cid Knipel Moreira. São Paulo: Companhia das Letras, 1998.

LE GOFF, Jacques. História e memória. 4. ed. Campinas, SP: Editora da UNICAMP, 1996.

MARX, Karl. Elementos fundamentales para la crítica de la economía política (Grundrisse) 1857-1858. Vol. 1. 14. ed. México, Buenos Aires, Madrid, Bogotá: Siglo Veintiuno, 1986a.

MARX, Karl. Elementos fundamentales para la crítica de la economía política (Grundrisse) 1857-1858. Vol. 2. 10. ed. México, Buenos Aires, Madrid, Bogotá: Siglo Veintiuno, 1985.

MARX, Karl. Elementos fundamentales para la crítica de la economía política (Grundrisse) 1857-1858. Vol. 3. 8. ed. México, Buenos Aires, Madrid, Bogotá: Siglo Veintiuno, 1986b. 
THOMPSON, E. P.. As peculiaridades dos ingleses e outros artigos. Orgs. Antonio Luigi Negro e Sérgio Silva. Campinas, SP: Editora da Unicamp, 2001.

VIÑAO FRAGO, Antonio. Historia de la educación e historia cultural: posibilidades, problemas, cuestiones. Revista Brasileira de Educação, n. 0, p. 63-82, set/dez 1995.

VIÑAO FRAGO, Antonio. Espacio y tiempo, educación e historia. Morella, México: IMCED, 1996.

${ }^{1}$ Palestra proferida em 28 de julho de 2011 na mesa redonda, com esse título, da X Jornada Nacional do HISTEDBR, em Vitória da Conquista, BA, de 26 a 29 de julho de2011.

Recebido: fevereiro-16 $\quad$ Aprovado: $\quad$ março-16 